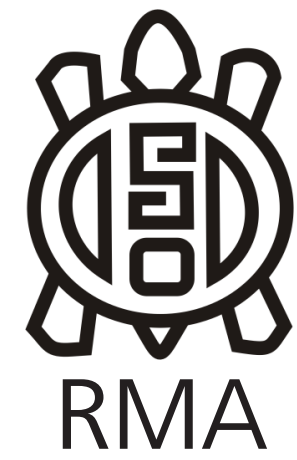

Arqueología

\title{
Abrigos puneños y sociedades agropastoriles: una perspectiva zooarqueológica del Alero 12 (Las Grutas, Tinogasta, Catamarca)
}

\author{
Puna shelters and agro-pastoral societies: a zooarchaeological \\ perspective of Alero 12 site (Las Grutas, Tinogasta, Catamarca)
}

Juan Pablo Miyano* y Norma Ratto**

*Instituto de las Culturas (IDECU) (UBA-CONICET). E-mail: jpmiyano@gmail.com

**Instituto de las Culturas (IDECU) (UBA-CONICET). E-mail: nratto@filo.uba.ar

\begin{abstract}
Resumen
Este trabajo analiza el conjunto arqueofaunístico del Alero 12 de la formación rocosa Las Grutas (Tinogasta, Catamarca) para dar cuenta de las actividades humanas vinculadas a los animales que se desarrollaron durante su ocupación. Se sostiene que los grupos humanos que usaron el alero hace ca. 590 años AP lo hicieron de manera temporal. Alli, cazaron animales silvestres, fundamentalmente vicuñas, aunque no se descarta el aprovechamiento de aves y roedores. Mientras ciertas partes esqueletarias de Camelidae fueron consumidas in situ, otras fueron transportadas para su consumo diferido, almacenamiento y/o intercambio. Si bien el Alero 12 presenta un fechado que coincide con la ocupación incaica de la región y se encuentra próximo al sitio San Francisco -vinculado a eventos festivos promovidos por el incario-, su uso no se relaciona con prácticas imperiales. En este sentido, se propone que quienes utilizaron el alero fueron integrantes de las sociedades agropastoriles de la región que desarrollaron actividades de caza por fuera del control incaico.
\end{abstract}

Palabras clave: Camélidos; Vicuña; Caza; Noroeste argentino; Inca

\begin{abstract}
This article analyses the archaeofaunal assemblage from Alero 12 of the Las Grutas rock formation (Tinogasta, Catamarca) to study/account for the human activities related to animals that developed during its occupation. We suggest/It is argued that Alero 12 was temporarily inhabited by human groups ca. 590 years BP. At the site, they hunted wild animals, mainly vicuñas, although birds and rodents cannot be ruled out. While some camelid skeletal parts were consumed in situ, others were transported for later consumption, storage and/or trading. Although Alero 12 is located near to the San Francisco site - a site used for state sponsored feasts-and also presented a radiocarbon date that coincides with Inca occupation of the region, its use was not related to imperial practices. In this sense, we propose that the inhabitants of Alero 12 were members of the regional agropastoralist societies that developed hunting activities outside of inca control.
\end{abstract}

Keywords: Camelids; Vicuña; Hunting; Northwest Argentina; Inca

\section{Introducción}

La ocupación de aleros y cuevas por las sociedades cazadoras recolectoras de la puna argentina se encuentra ampliamente documentada (Aschero y Yacobaccio 1998-1999; Elkin 1995a; Olivera 1997; Yacobaccio 1994; Yacobaccio et al. 2000; entre otros). El paso a un modo de vida agropastoril con residencias de ocupación permanente no supuso el abandono del uso de dichos abrigos rocosos. Distintos análisis zooarqueológicos permitieron abordar las actividades humanas vinculadas a los animales desarrolladas en esos tipos de sitios. En su mayoría se trata de ocupaciones breves relacionadas con tareas de caza y/o pastoreo. Asimismo, estos sitios también pudieron haber funcionado como nodos en redes de intercambios regionales e incluso como loci de desarrollo de prácticas rituales (Cordomí 2012; Erramouspe et al. 2017; López, 2009 a y b; López et al. 2015; Olivera y Grant 2008, 2009; Urquiza y Aschero 2014; Yacobaccio et al. 1997-1998; Yacobaccio et al. 2012; entre otros). En este sentido, la combinación de los estudios zooarqueológicos con la información contextual a escala local y regional resulta fundamental para interpretar las actividades desarrolladas en este tipo de sitios, así como también para inferir su funcionalidad. 
En este trabajo analizamos el conjunto arqueofaunístico recuperado tras la excavación del Alero 12 de la formación rocosa Las Grutas, ubicado en la puna transicional de Chaschuil (Tinogasta, Catamarca). La ocupación de la que proviene dicho conjunto cuenta además con una característica particular: presenta un fechado de 590 años $A P$, coincidiendo con la presencia incaica en la región. Así, el trabajo busca dar cuenta de las actividades realizadas en el alero vinculadas a los animales, para lo cual articulamos los estudios arqueológicos realizados tanto en el sitio como en otros cercanos y los antecedentes extrarregionales del uso de abrigos rocosos por sociedades agropastoriles.

\section{El uso de cuevas y aleros en la puna argentina por sociedades agropastoriles (ca. 3000-400 años AP)}

El uso de cuevas y aleros no fue abandonado tras la incorporación de componentes productivos a la economía de los grupos humanos que ocuparon la puna argentina. Respecto a esto, los estudios realizados en distintos sectores de ese espacio muestran la variabilidad en las actividades desarrolladas en abrigos rocosos, las cuales deben ser comprendidas considerando los contextos particulares.

En la puna de Jujuy, las investigaciones realizadas en Susques muestran que Cueva Chayal, Cueva Quispe y el alero Huirunpure fueron utilizados por pastores entre los ca. 2600-410 años AP donde desarrollaron actividades relativamente acotadas en el tiempo y vinculadas al manejo de llamas y a la caza de camélidos silvestres y otros animales de menor porte, como vizcachas. Si bien las ocupaciones fueron breves, se destaca la reutilización de los mismos espacios a lo largo de amplios períodos (e.g. Cueva Chayal presenta ocupaciones entre ca. 1080 y 410 años AP) (Yacobaccio et al. 1997-1998, 2012). Hacia el norte de estos tres sitios se emplaza Alero Caído 1, interpretado como un puesto de altura y/o lugar de paso donde un número reducido de personas realizaron actividades estacionales de pastoreo, intercambio de recursos y caza de vicuñas entre los ca. 3000-2500 años AP (Erramouspe et al. 2017). Finalmente, en el sector oriental de la puna jujeña se ubica Alero Tomayoc que, hacia los ca. 1000-550 años AP, funcionó como una instalación estacional caza-pastoreo vinculada con sitios de cotas altitudinales menores, posiblemente de la Quebrada de Humahuaca. Además, se constituyó como un punto de referencia dentro del circuito caravanero regional (Lavallée et al. 1997; Olivera y Grant 2009).

En la puna de Salta, la ocupación de Alero Cuevas (ca. 2000-640 años AP) se vinculó directamente con la caza de vicuñas dada la amplia presencia de restos óseos de este camélido. Sin embargo, también se realizaron actividades de pastoreo considerando no solo los especímenes de Lama glama identificados sino también los corrales emplazados en el área (López 2009 a y b).
En tanto, Cueva Inca Viejo presenta distintos diseños de arte rupestre, destacándose los motivos de caravanas de llamas. Así la ocupación de ca. 860 años AP fue vinculada a la estadía de caravaneros quienes trasladaron recursos exóticos (e.g. semillas de cebil y plumas de aves de las yungas), desarrollaron prácticas rituales y consumieron camélidos durante sus estadías (López et al. 2015). La cueva fue reocupada durante momentos incaicos (ca. 430 años AP), siendo modificada para el desarrollo de actividades mineras (socavones y galerías secundarias) y prácticas ceremoniales (construcción de una estructura ceremonial o ushnu) (López et al. 2018).

Finalmente, y en la puna de Catamarca, Olivera y Grant (2009) abordaron las arqueofaunas de los aleros Real Grande 1 y 6 . Estos sitios, cuyas ocupaciones datan entre los años ca. 1170-440 años AP, se caracterizan por presentar conjuntos óseos dominados por especímenes de Vicugna vicugna, sin registrarse otra especie de camélido. Así, fueron interpretados como puestos de altura de caza-pastoreo relacionado con sitios de ocupación anual emplazados en cotas altitudinales menores (Olivera 1997). En tanto, la Cueva Cacao I exhibe la misma tendencia para su ocupación de ca. 990 años AP: predominancia de vicuñas (Olivera y Grant 2008). Cabe señalar que esta cueva presenta una ocupación de carácter ritual previa, fechada para los inicios del modo de vida agropastoril (ca. 3000-2800 años AP) (Olivera et al. 2003). Finalmente, el alero Punta de la Peña 4 fue ocupado entre los ca. 1000-460 años AP por grupos agropastoriles que desarrollaron fundamentalmente actividades de pastoreo de llamas y de caza de vicuñas. El consumo de camélidos fue complementado con el de aves y roedores locales aprovechados de manera oportunista (Cordomí 2012; Urquiza y Aschero 2014; Urquiza y Echevarría 2018).

En síntesis, la ocupación de cuevas y aleros por sociedades agropastoriles prehispánicas se encuentra ampliamente documentada en la puna argentina entre los ca. 3000-400 años AP. En general, estos abrigos rocosos formaron parte de un sistema de asentamientos que involucró otros sitios, siendo sus ocupaciones de carácter estacional/temporaria y posiblemente reocupados años tras año. Las actividades allí realizadas se vincularon al pastoreo de llamas y a la caza de vicuñas. No obstante, en ciertos casos se ha registrado el aprovechamiento de otros animales silvestres disponibles de manera inmediata. Asimismo, este tipo de ocupaciones también pudieron haber estado relacionadas con el tráfico de bienes y recursos, proveyendo refugio a los caravaneros en sus travesías interregionales.

\section{La región de estudio: la puna transicional de Chaschuil}

La puna transicional de Chaschuil se ubica en el oeste tinogasteño (Catamarca) y se encuentra limitada por las sierras de Las Planchadas y de Narváez al este, 
la cordillera de San Buenaventura al norte, las altas montañas y volcanes de la cordillera de los Andes al oeste $y$, arbitrariamente, por la cota altitudinal de 3500 msnm en el área de Cazadero Grande (Ratto 2013) (Figura 1). Actualmente se caracteriza por presentar un clima semiárido con una precipitación media anual menor a 100 $\mathrm{mm}$, concentrada en el período estival. La temperatura media anual varía entre $2-7{ }^{\circ} \mathrm{C}$ (con una media de 7-12 ${ }^{\circ} \mathrm{C}$ en el mes más caluroso y de $-5-0{ }^{\circ} \mathrm{C}$ en el mes más frío) (Bianchi y Cravero 2010). Respecto a la vegetación, presenta características fitogeográficas de las Provincias de la Puna y Altoandina (Cabrera y Willink 1973; Morlans 1985). Siguiendo a Vervoorst (1951), las unidades de vegetación dominantes son la estepa arbustosa (entre los 3500-3800 msnm) y la estepa graminosa (entre los 3800-4300 msnm) siendo su distribución heterogénea: existen extensas áreas sin cobertura vegetal y espacios acotados con una alta densidad de plantas como las vegas de altura. La presencia de agua y la concentración de vegetación transforman a las vegas de altura en espacios atractivos para animales silvestres, especialmente vicuñas (Ratto 2003).

La evidencia arqueológica proveniente tanto de superficie como de excavaciones de sitios indica que la ocupación prehispánica de la puna transicional de Chaschuil ocurrió en un amplio rango temporal, abarcando desde los cazadores recolectores de ca. 8600 años AP (Ratto 2003) hasta la llegada del imperio inca (Orgaz 2002; Ratto et al. 2012). Este último evento de la ocupación humana de la región es el de interés para el presente trabajo. La llegada de los incas al oeste tinogasteño resultó en un complejo entramado social, cultural y demográfico. Esto se debe a que las prácticas imperiales convivieron con las de las poblaciones movilizadas por el incario desde los valles del oriente (Belén) y del norte La Rioja en el marco de sus estrategias de dominación así como también con las de las sociedades agropastoriles locales. Respecto a estas últimas, se ha propuesto una repetitividad en sus prácticas desde inicios del primer milenio de la era hasta el ingreso de los incas en la región, dándose así un "Formativo extendido" que desafía los límites de las periodizaciones clásicas del desarrollo cultural del noroeste argentino (Orgaz y Ratto 2013, 2015; Ratto 2013).

\section{El sitio Alero 12 de la formación rocosa Las Grutas}

El Alero 12 de la formación rocosa Las Grutas (A12) se ubica en la puna transicional de Chaschuil (Figura 1) a unos $60 \mathrm{~m}$ hacia el oeste de la vega de San Francisco y a 3980 msnm. A12 es uno de los 15 aleros que componen

Figura 1. Puna transicional de Chaschuil (Catamarca) y área destacada con los sitios mencionados en el presente trabajo. A12: Alero 12; SF-IK: Inca; LCv-1: Las Cuevas 1; LC: Las Coladas; SF-04: San Francsico-04; F1: Fiambalá 1.

Figure 1. Transitional puna of Chaschuil (Catamarca) and highlighted area with the sites mentioned in this paper. A12: Alero 12; SF-IK: Inca; LCv-1: Las Cuevas 1; LC: Las Coladas; SF-04: San Francsico-04; F1: Fiambalá 1.
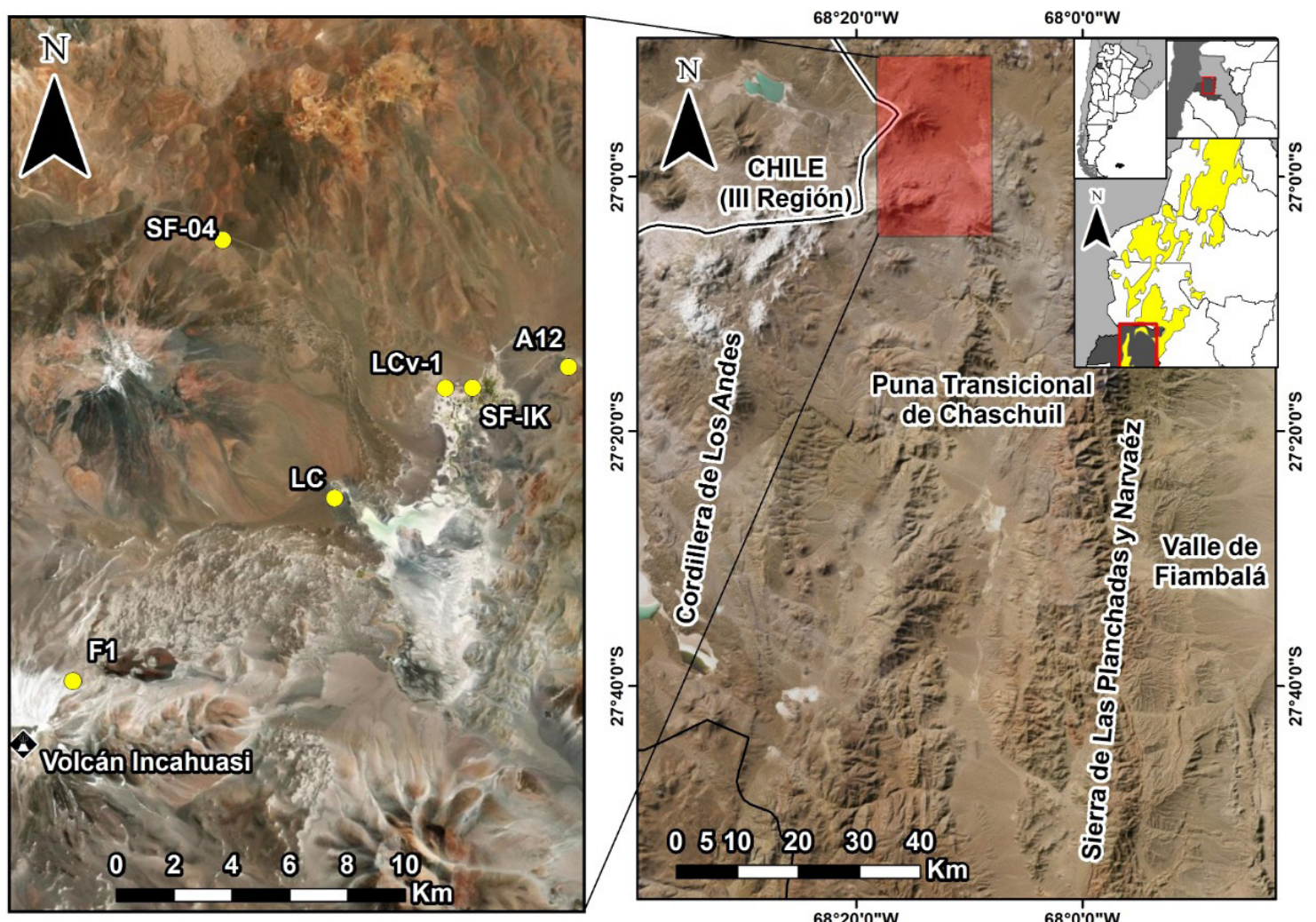

ISSN 1852-060X (impreso) / ISSN 1852-4826 (electrónico) 
la formación rocosa Las Grutas; posee 9 m de largo y 4,9 $m$ de ancho y se encuentra parcialmente cerrado por un pircado cuyo momento de construcción es desconocido (Ratto 1997) (Figura 2). Los análisis geoarqueológicos destacan que la intensidad de la ocupación humana del sitio fue baja y se concentró en la unidad estratigráfica III (UEIII), donde se realizaron actividades breves y discretas en el tiempo (Kligmann 2009).

La UEIII de A12 presenta un fechado radiocarbónico de 590 \pm 45 años AP (LP-880, carbón) (Ratto 1997) lo que ubica esta ocupación en momentos de la presencia incaica en la región. Mediante su excavación se recuperó el conjunto arqueofaunístico analizado en este trabajo (ver más adelante) así como también materiales líticos y cerámicos. Respecto al material lítico, el conjunto artefactual fue estudiado por Luna (2001) y se compone fundamentalmente de desechos $(\mathrm{N}=387)$, siguiéndole en importancia instrumentos $(\mathrm{N}=10)$ y núcleos $(\mathrm{N}=4)$ y dominando las materias primas volcánicas de origen local. Entre los instrumentos se destacan dos fragmentos de cabezales líticos, tres raspadores, un cuchillo, tres piedras de moler y un mortero. Considerando este conjunto, Luna (2001) sostiene que en el alero se realizaron tareas de formatización y mantenimiento de instrumentos, así como también se delimitó un espacio destinado a la molienda. Respecto al material cerámico, se recuperaron dos fragmentos de pasta oxidante, alisados, sin decoración, posiblemente de la misma pieza ordinaria (Ratto 1997). Por último, Kligmann et al. (1999) Ilevaron a cabo un análisis tafonómico de los microvertebrados (fundamentalmente, Reptilia), concluyendo que su incorporación a la UEIII fue por causas naturales (muerte durante hibernación) y no por transporte humano.

El Alero 7 de la misma formación rocosa (A7) presenta también un análisis tafonómico. En este caso, el estudio fue realizado sobre un conjunto de 65 especímenes óseos de macrovertebrados de superficie, compuesto por restos de Camelidae, Artiodactyla e indeterminados de Mammalia. El análisis tafonómico permitió sostener una alta redundancia en el uso del sitio por humanos y carnívoros, resultando en un conjunto de baja integridad y resolución (Mondini 1997). Además, este alero posee un fechado de 410 \pm 60 años AP (LP-864, carbón) (Ratto et al. 2012). En tanto, los aleros 1, 2, 5, 6, 8, 9, 12, 13, 14 y 15 también presentaron restos óseos en superficie siendo los de A5 y A6 los más numerosos (532 y 920 especímenes, respectivamente). La composición taxonómica de ambos conjuntos evidencia una predominancia de Camelidae, siguiéndole en menor frecuencia Rodentia, Aves y Lycalopex sp. (Ratto 1997). El resto de los aleros exhibió entre uno y 58 especímenes en superficie, presentando A12 solo 33 (13 de ellos Camelidae y el resto indeterminados).

La ocupación de A12 fue contemporánea a otros sitios del norte de las tierras altas del oeste tinogasteño. Entre ellos se destacan San Francisco, Las Coladas, San Francisco-04 y Fiambalá 1 (Figura 1); todos ellos (a excepción de San Francisco-04) fueron asociados con la ruta de ascenso al volcán Incahuasi (6632 msnm) donde se registró un santuario de altura. Asimismo, San Francisco, San Francisco-04 y Fiambalá 1 son sitios multicomponentes que presentan ocupaciones previas. De esta manera, el Estado Inca se instaló sobre estructuras preexistentes de los grupos agropastoriles locales sin modificarlas (San Francisco-04 y Fiambalá 1) o reformulándolas (San Francisco), apropiándose así de los espacios con historia previa (Orgaz y Ratto 2013).

San Francisco (4000 msnm) presenta un patrón

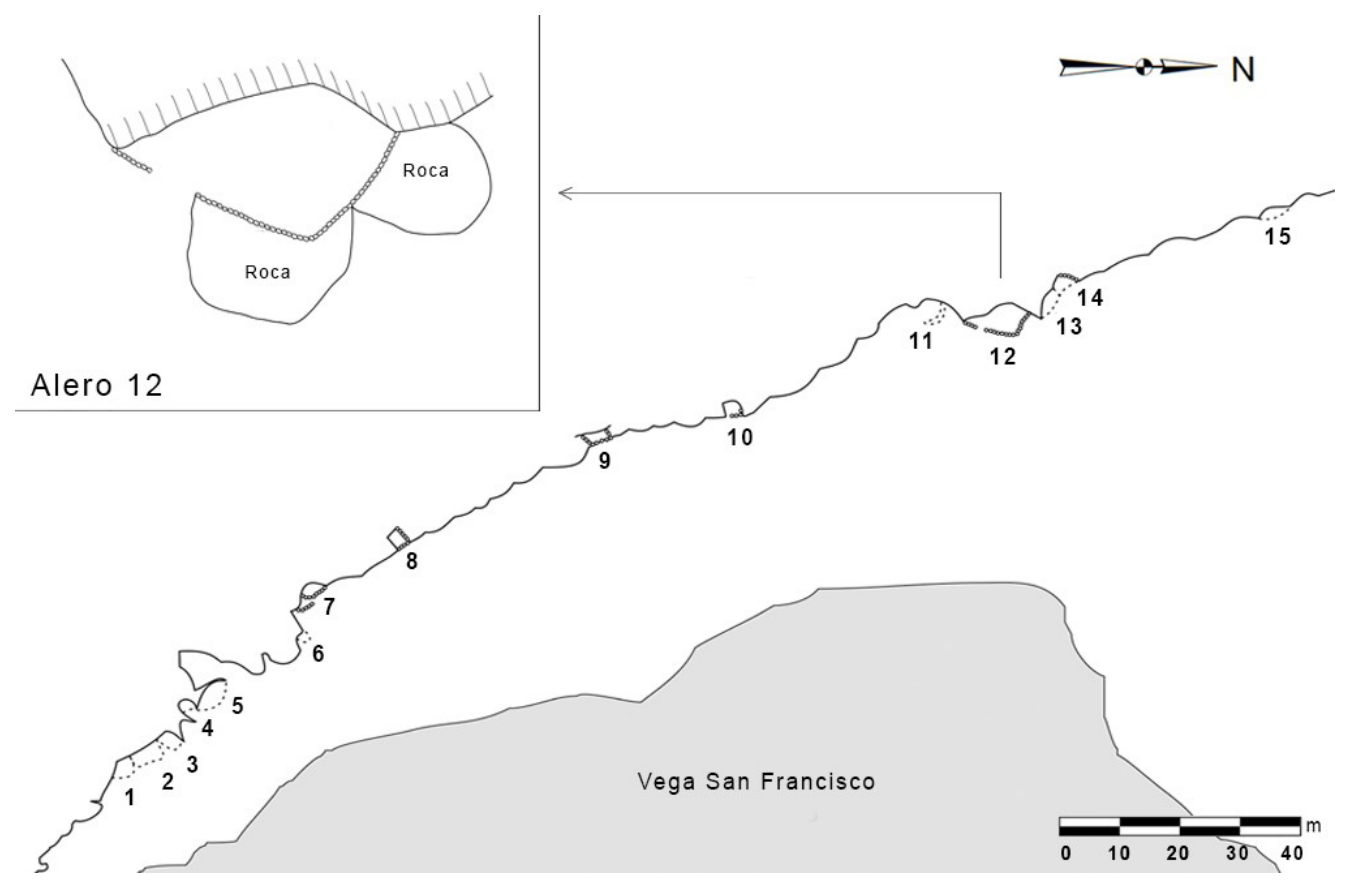

Figura 2. Plano de la formación rocosa Las Grutas y detalle del Alero 12. Relevamiento realizado por José Carreras en el año 1996. Tomado y modificado de Kligmann (2009)

Figure 2. Plan of the rock formation of Las Grutas and detail of Alero 12. Survey carried out by José Carreras in 1996. Taken and modified from Kligmann (2009) 
arquitectónico de tipo RPC (sensu Madrazo y Ottonello 1966). Allí se celebraron actividades ceremoniales restringidas y patrocinadas por el Estado donde se consumieron y compartieron bebidas alcohólicas y alimentos (Orgaz et al. 2007, Lantos et al. 2015). El registro zooarqueológico indica que el consumo de alimentos se concentró en animales silvestres capturados localmente (fundamentalmente, vicuñas adultas) (Miyano et al. 2017). Los fechados correspondientes a esta ocupación incaica son $570 \pm 60$ años AP (LP-3173, hueso) y 570 \pm 50 años AP (LP-3169, hueso) (Miyano et al. 2017). Cabe señalar que a $60 \mathrm{~km}$ hacia el sur del sitio (área de Cazadero Grande) se registraron dos macroestructuras utilizadas durante momentos incaicos en la cacería comunal regulada de vicuñas mediante el chaku y/o lipi (Ratto y Orgaz, 2002-2004). Así, se ha propuesto que la cacería colectiva también pudo ocurrir durante la ocupación incaica de San Francisco dado el perfil etario de las vicuñas (Miyano et al. 2017).

Las Coladas (4200 msnm) también se caracteriza por mostrar un patrón arquitectónico tipo RPC y por presentar cerámica imperial (Inca mixto y provincial). Si bien no presenta fechados radiocarbónicos, la evidencia diagnóstica señalada permitió considerarlo como un asentamiento incaico (Ratto et al. 2002). El análisis de un fragmento de aribaloide indica que la vasija contuvo chicha y aloja (Lantos et al. 2015). Así, y al igual que en San Francisco, también se propuso que en Las Coladas se desarrollaron prácticas festivas (Ratto y Orgaz 2009). Desafortunadamente, los restos arqueofaunísticos son escasos (NISP=22), pero se han podido registrar especímenes de vicuñas y aves (Miyano 2019).

El sitio San Francisco-04 (4558 msnm) se compone de cinco estructuras subcirculares adosadas, aprovechando afloramientos rocosos naturales. Por su emplazamiento, el sitio se relaciona con la ruta de ascenso al volcán San Francisco, funcionando posiblemente como parte de una red logística de sitios en dicho camino. La ocupación adscripta a momentos incaicos presenta un fechado radiocarbónico de 380 37 años AP (AA93279, hueso) (Ratto et al. 2012). El conjunto arqueofaunístico es sumamente escaso, destacándose una falange de vicuña que fuera utilizada para fechar la ocupación.

Fiambalá 1 (5000 msnm) se compone de cinco estructuras subcirculares. Su ubicación en un ambiente extremo y su reocupación a lo largo del tiempo (primer y segundo milenio de la era) llevaron a postular que se realizaron actividades ceremoniales vinculadas al culto a los cerros. Durante momentos incaicos, los estudios geoarqueológicos sugieren que la ocupación fue efímera y sin generación de residuos por lo que funcionó también como un sitio de pernocte previo ascenso al santuario de altura del volcán Incahuasi (Kligmann y Ratto 2009; Ratto y Orgaz 2009). Los fechados radiocarbónicos correspondientes a estos momentos son tres: $504 \pm 36$
(AA81739, gramínea), 458_49 (AA81741, gramínea) y 465 \pm 34 años AP (AA69977, gramínea) (Ratto y Orgaz 2009). No se registraron restos arqueofaunísticos para la ocupación incaica.

Por último, cabe destacar que Las Cuevas 1 (4020 msm) (Figura 1), un alero emplazado en otras formaciones rocosas que circundan a la vega de San Francisco, presenta la particularidad de que fue modificado en la década de 1980 para la construcción del campamento minero Los Conos. Dada la cementación del piso no fue posible realizar excavaciones; no obstante, se obtuvo un fechado de una gruesa capa de hollín del techo del alero que adscribe su uso a momentos incaicos: $419 \pm 76$ años AP (AA69978, hollín) (Ratto et al. 2012).

En suma, los animales silvestres locales parecen haber sido los aprovechados durante la ocupación incaica de la puna transicional de Chaschuil, considerando la amplia información zooarqueológica de San Francisco y la escueta de Las Coladas y San Francisco-04. En este sentido, el análisis del conjunto arqueofaunístico del A12 permitirá comprender cuáles fueron las actividades vinculadas a los animales allí desarrolladas y evaluarlas considerando la presencia incaica de la región.

\section{Materiales y métodos}

La excavación del A12 se realizó a partir de una cuadrícula de $4 \mathrm{~m}^{2}$, alcanzando los $80 \mathrm{~cm}$ de potencia (Ratto, 1997). El conjunto arqueofaunístico recuperado proviene de la unidad estratigráfica III (A12-UEIII), de $60 \mathrm{~cm}$ de potencia, y se compone de un total de 1321 restos óseos. Los criterios metodológicos para el análisis del conjunto A12UEIII se detallan a continuación.

En primer lugar, la cuantificación los especímenes óseos (NSP) se realizó mediante la suma de aquellos que pudieron ser identificados anatómica y taxonómicamente (NISP) (Lyman 1994) y de aquellos que no (NID) (Mengoni Goñalons 1999). En el caso de los especímenes asignados a Camelidae, dos dimensiones medidas de manera perpendicular en una misma porción del elemento óseo arqueológico fueron comparadas con sus equivalentes de muestras de referencia. Las dimensiones consideradas fueron: FP1V2 y FP1V3 para falange 1; SCA165 y SCA166 para escápula; TIB102 y TIB103 para tibia; MTARS30 y MTARS31 para metatarso; y RAUL144 y RAUL142 para radioulna (Kent 1982). Respecto a las muestras de referencia, se utilizaron camélidos actuales de la provincia de Catamarca: una vicuña, un guanaco (Mondini y Muñoz 2017) y una llama (Izeta 2007).

En segundo lugar, y respecto a la abundancia anatómica de Camelidae, a partir del NISP se calcularon MNE, MAU y \%MAU (Binford 1984). Para construir el MNE se combinaron los métodos de zonas diagnósticas (Mengoni Goñalons 1999) y la suma de fracciones (Klein 
y Cruz-Uribe 1984). Además, se calcularon las Partes Esqueletarias Básicas (PEB) (Yacobaccio et al. 19971998) sumando las frecuencias del MNE de distintos elementos óseos agrupados según las zonas principales del esqueleto (cabeza, columna, costillar, pelvis, escápula, pata y pie delanteros, pata y pie traseros, falanges). En tanto, los valores de \%MAU fueron correlacionados (rho de Spearman) con distintos índices: de Carne (IC) (Borrero 1990), de Médula Ósea (IM) (Mengoni Goñalons y De Nigris 1999), de Secado (IS) (De Nigris y Mengoni Goñalons 2005) y de Densidad Mineral Ósea (DMO) (Elkin 1995b).

En tercer lugar, se evaluaron las clases de edad de Camelidae. Para ello se consideraron los elementos óseos presentes en el cronograma de fusión propuesto por Mengoni Goñalons (2013). Así, los especímenes arqueológicos correspondientes fueron asignados a alguna de las tres etapas de fusión (temprana, <12-18 meses; intermedia, <18-36 meses; tardía, <36-48 meses) considerando el tipo de fusión exhibido (fusionado o no fusionado).

En cuarto lugar, y considerando el NISP total, se registraron las modificaciones óseas de origen antrópico (corte, machacado, raspado, percusión, lascados) (De Nigris 2004; Mengoni Goñalons 1999), de origen no antrópico (roedores, carnívoros, raíces, pisoteo) (Mengoni Goñalons 1999), los estadios de meteorización (Behrensmeyer 1978) y termoalteración (Mengoni Goñalons 1999).

Por último, se abordó la fragmentación a partir de dos índices. Por un lado, la fragmentación general del conjunto se evaluó mediante la relación NSP:NISP (Lyman 2008). Por otro lado, la intensidad de la fragmentación del subconjunto Camelidae se estimó mediante la relación NISP:MNE (Lyman 1994) tanto para el esqueleto completo como para el apendicular y axial por separado. Para ello no se consideraron elementos como sesamoideos, dientes y cartílago intercostal.

\section{Resultados}

\section{Abundancia y diversidad taxonómica}

El conjunto arqueofaunístico se compone de 1321 especímenes (NSP), de los cuales 249 (18,8\%) corresponden al NISP y 1072 (81,2\%) al NID; observándose así un bajo índice de identificación. Dentro del NISP, los restos óseos de Camelidae son los más abundantes (NISP=120), representando un 48,2\% de dicho conjunto. Le siguen en importancia los especímenes de Artiodactyla (NISP=117; $47 \%)$. Finalmente, se registraron, en mucha menor frecuencia, restos de Mammalia (NISP=7; 2,8\%), Rodentia $(\mathrm{NISP}=3 ; 1,2 \%)$, Chinchillidae (NISP=1;0,4\%) y Aves $(\mathrm{NISP}=1 ; 0,4 \%)$.

El análisis osteométrico muestra que seis especímenes arqueológicos de distintos elementos óseos se relacionan por sus medidas con la vicuña de referencia, alejándose claramente del guanaco y la llama (Figura 3). Cabe señalar que la llama de referencia consultada no presenta medidas para el caso del metatarso ni de la tibia por lo que no pudieron incluirse para su comparación. Sin embargo, en ambos casos los dos especímenes arqueológicos presentan tamaños similares a la vicuña de referencia (metatarso proximal) o incluso menores (tibia distal). Así, en el subconjunto Camelidae de $\mathrm{A} 12$ solo fue registrado este camélido silvestre.

\section{Abundancia y diversidad anatómica de Camelidae}

La gran mayoría de las partes esqueletarias de Camelidae están representadas en A12-UEIII. Con respecto al esqueleto axial, solo se encuentran ausentes algunos elementos de la columna: atlas, axis, vértebras torácicas y sacro. Respecto al esqueleto apendicular, se registró la ausencia de solo dos elementos: rótula y metacarpo proximal. Así, se destaca la gran representación de esqueleto de Camelidae lo que sugiere que los animales fueron ingresados completos al alero.

Sin embargo, se observa una distribución heterogénea si se consideran las zonas mayores: el esqueleto apendicular domina sobre el axial tanto considerando el NISP (65\% y $35 \%$, respectivamente) como el MNE (78,3\% y 21,7\%, respectivamente) (Tabla 1). Esta predominancia también se observa al analizar las PEB en donde las mayores frecuencias corresponden al esqueleto apendicular (Figura 4). Esta representación diferencial de las partes esqueletarias no se encuentra influida por la densidad mineral ósea de los distintos elementos dado que las correlaciones entre el \%MAU y los valores de DMO (Elkin 1995b) fueron bajas y no significativas (tanto para el esqueleto completo $\left[r_{s}=0,35 ; p>0,05\right]$ como para el esqueleto axial $\left[r_{s}=-0,44 ; p>0,05\right]$ y apendicular $\left[r_{s}\right.$ 0,20; $p>0,05]$ por separado) (Marean y Frey 1997).

Las correlaciones realizadas con el IC, tanto para el esqueleto completo como para el esqueleto axial, fueron moderadas-bajas y no significativas $\left(r_{s}=0,04 ; p>0,05\right.$ y $r_{s}=-0,40 ; p>0,05$, respectivamente). En tanto, la correlación con el IC para el esqueleto apendicular fue moderada-alta, positiva y significativa $\left(r_{s}=0,52\right.$; $\mathrm{p}<$ $0,05)$ lo que sugiere que la frecuencia de huesos del esqueleto apendicular puede explicarse por la utilidad de carne. Esto es consistente con la representación del fémur y húmero en el conjunto (Tabla 1), huesos largos con la mayor cantidad de carne asociada. En tanto, la correlación con el IM fue alta, positiva y significativa $\left(r_{s}=\right.$ $0,82 ; p<0,05)$ por lo que la representación de los huesos largos no solo puede explicarse por la utilidad de carne sino también por el contenido de médula. Finalmente, la correlación con el IS fue alta, negativa y significativa $\left(r_{s}=-0,88 ; \mathrm{p}<0,01\right)$ lo que indica que las unidades anatómicas más apropiadas para el secado con hueso se encuentran escasamente representadas. El resultado de esta correlación se atribuye a la escasez y/o ausencia 
Figura 3. Análisis osteométrico bivariado de cinco elementos del esqueleto apendicular de Camelidae del conjunto A12UEIII

Figure 3. Bivariate osteometric analysis of five elements of the appendicular skeleton of Camelidae from the A12-UEIII assemblage

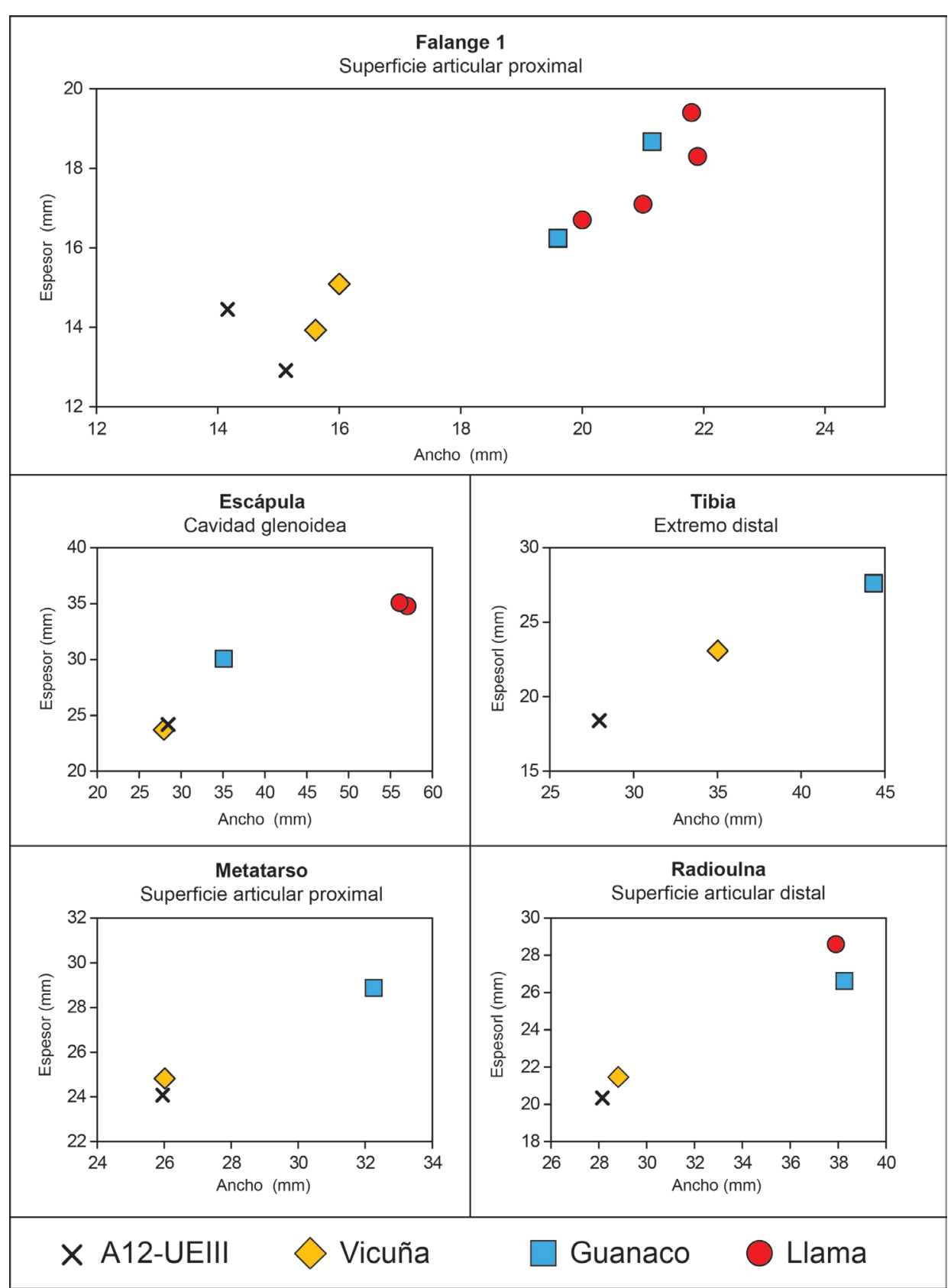

de los distintos elementos que componen el costillar y la columna o a su alta fragmentación (ver más adelante).

\section{Clases de edad de Camelidae}

En la primera categoría etaria (<12-18 meses) solo se registran especímenes fusionados lo cual indica la supervivencia de estos animales a los 18 meses de edad. En las siguientes dos categorías etarias, los especímenes fusionados y no fusionados se distribuyen de manera relativamente pareja. Estos datos indican que entre un 50$57 \%$ de estos animales sobrevivieron a los 36-48 meses de edad (Tabla 2). Así, se observa una leve predominancia de camélidos adultos, mayores a los 3-4 años. En relación con el resto, podrían tratarse de animales de distintas edades entre los 12 y 36 meses.

\section{Modificaciones óseas}

Las marcas de origen antrópico se registraron solo sobre especímenes de Artiodactyla y Camelidae. Respecto al subconjunto Artiodactyla, se identificaron especímenes con evidencia de percusión (7:117), correspondiendo todos ellos a fragmentos de huesos largos y posiblemente se encuentren relacionados con la extracción de médula ósea. Respecto al subconjunto Camelidae, se identificaron especímenes con marcas de corte (8:120), machacado (1:120) y percusión (6:120). Por un lado, las marcas de corte se ubican en especímenes óseos correspondientes a elementos tanto del esqueleto axial (pelvis, costilla) como del apendicular (fémur, escápula, cuboide y ectocuneiforme). Por otro lado, la marca de machacado fue identificada en un fragmento de costilla. Finalmente, las marcas de percusión fueron registradas únicamente 
en elementos correspondientes al esqueleto apendicular (fémur, metapodio y falange 1). La ubicación de estos tres tipos de marcas en los distintos elementos óseos sugiere la realización de actividades de desarticulación, descarne y extracción de médula. Finalmente, resulta interesante destacar que un espécimen óseo de Artiodactyla presenta evidencias sobre la superficie ósea que sugieren su formatización. Específicamente se trata de un fragmento de hueso largo que exhibe un extremo en punta, redondeada, pulida y con estrías de orientación oblicua. La evidencia de percusión en huesos largos tanto de Camelidae como Artiodactyla pueden estar vinculadas no solo a la extracción de médula sino también a la obtención de formas base para la manufactura de instrumentos óseos.

Respecto a la termoalteración, el 12,8\% del NISP (32:249) exhibe algún tipo de evidencia de su exposición a una fuente de calor. Concretamente, el $2,4 \%$ se presenta quemado (6:249), el 7,6\% carbonizado (19:249) y el 2,8\% calcinado (7:249). En el caso de Camelidae, los especímenes termoalterados registrados son 10 y corresponden a dientes, huesos largos (húmero y metapodio), cinturas (pelvis y escápula), huesos articulares (carpianos y tarsianos) y vértebras cervicales.

En relación con la meteorización, el 76,7\% del NISP (191:249) exhibe estadio 0. En tanto el resto de los especímenes presentan estadio 1 (31:249; 12,5\%), 2 (23:249; 9,2\%) y, en mucha menor frecuencia, 3 (4:249; 1,6\%), no registrándose los estadios 4 y 5 .

Finalmente, y respecto a las modificaciones de origen no antrópico, el único agente modificador identificado fueron los roedores, dejando las marcas de sus incisivos en el $2,8 \%$ del NISP (7:249). No se identificaron marcas de carnívoros, raíces ni pisoteo.

\section{Fragmentación}

La fragmentación general del conjunto es alta, tal y como lo muestra el índice NSP:NISP con un valor de 5,31. Esto se vincula directamente con el bajo índice de identificación destacado al principio de esta sección. Respecto al subconjunto Camelidae, el índice NISP:MNE para el esqueleto completo es de 2,24. En tanto, el esqueleto axial muestra una fragmentación mayor que el

\begin{tabular}{|c|c|c|c|c|}
\hline \multirow{2}{*}{$\begin{array}{c}\text { Partes } \\
\text { esqueletarias }\end{array}$} & \multicolumn{4}{|c|}{ A12-UEIII } \\
\hline & NISP & MNE & MAU & $\% \mathrm{MAU}$ \\
\hline Dientes & 13 & - & - & - \\
\hline Cráneo & 4 & 1 & 1,00 & 50,00 \\
\hline Mandíbula & 1 & 1 & 0,50 & 25,00 \\
\hline Atlas & - & - & - & 0,00 \\
\hline Axis & - & - & - & 0,00 \\
\hline Cervicales & 3 & 2 & 0,40 & 20,00 \\
\hline Torácicas & - & - & - & 0,00 \\
\hline Lumbares & 2 & 1 & 0,14 & 7,14 \\
\hline Sacro & - & - & - & 0,00 \\
\hline Costillas & 13 & 3 & 0,13 & 6,25 \\
\hline Cartílago intercostal & 1 & - & - & - \\
\hline Esternebras & 1 & 1 & 0,17 & 8,33 \\
\hline Pelvis & 4 & 1 & 0,50 & 25,00 \\
\hline Subtotal Axial & 42 & 10 & - & - \\
\hline Escápula & 4 & 1 & 0,50 & 25,00 \\
\hline Húmero & 9 & 3 & 1,50 & 75,00 \\
\hline Radioulna & 3 & 2 & 1,00 & 50,00 \\
\hline Carpianos & 4 & 4 & 0,29 & 14,29 \\
\hline Fémur & 4 & 4 & 2,00 & 100,00 \\
\hline Rótula & - & - & - & 0,00 \\
\hline Tibia & 7 & 2 & 1,00 & 50,00 \\
\hline Tarsianos & 5 & 5 & 0,50 & 25,00 \\
\hline Astrágalo & 1 & 1 & 0,50 & 25,00 \\
\hline Calcáneo & 2 & 1 & 0,50 & 25,00 \\
\hline Metacarpo px & - & - & - & 0,00 \\
\hline Metatarso px & 4 & 2 & 1,00 & 50,00 \\
\hline Metapodio ind & 18 & 4 & 1,00 & 50,00 \\
\hline Falange 1 & 12 & 5 & 0,63 & 31,25 \\
\hline Falange 2 & 1 & 1 & 0,13 & 6,25 \\
\hline Falange 3 & 1 & 1 & 0,13 & 6,25 \\
\hline Sesamoideos & 3 & - & - & - \\
\hline Subtotal apendicular & 78 & 36 & - & - \\
\hline Total & 120 & 46 & - & - \\
\hline
\end{tabular}

Tabla 1. NISP, MNE, MAU y \%MAU de Camelidae del conjunto A12-UEIII

Table 1. NISP, MNE, MAU and\% MAU of Camelidae of the A12UEIII assemblage 


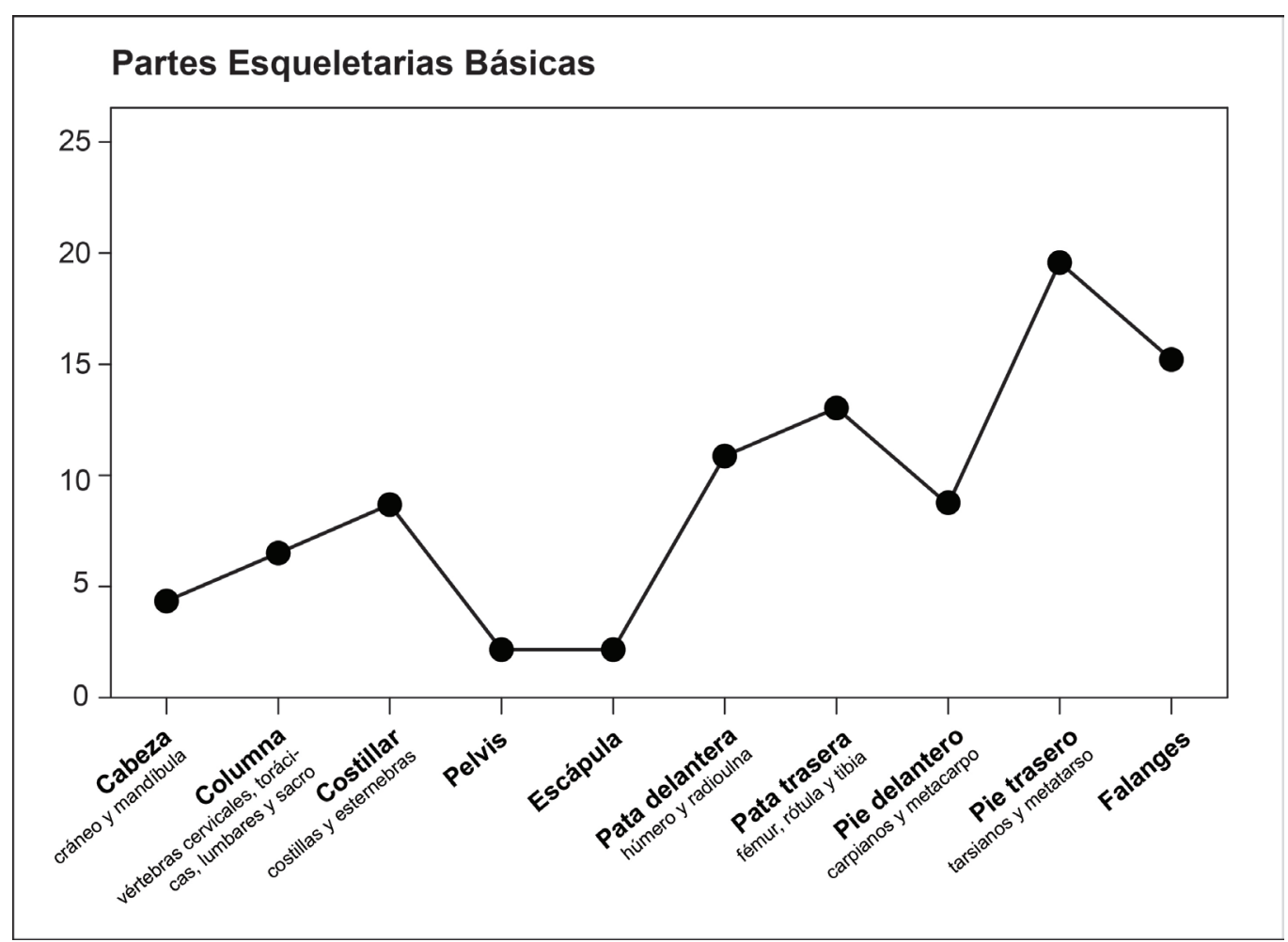

Figura 4. Representación de las Partes Esqueletarias Básicas (PEB) de Camelidae del conjunto A12-UEIII

Figure 4. Representation of the Basic Skeleton Parts of Camelidae from the A12-UEIII assemblage

esqueleto apendicular dado que los índices son de 2,80 y 2,08 respectivamente.

\section{Discusión y conclusiones}

La integridad del conjunto arqueofaunístico de A12 Como se ha destacado al inicio de este trabajo, Kligmann (2009) ha propuesto la alta integridad y resolución de la UEIII de A12 a partir de estudios geoarqueológicos y estratigráficos. Así, el análisis zooarqueológico permite evaluar dicho postulado a través de otro tipo de evidencia material.

La identificación de marcas de origen antrópico sobre especímenes de Artiodactyla y Camelidae y la evidencia de termoalteración indica que los humanos fueron los principales agentes en la formación del conjunto. Esto se refuerza al observar la frecuencia de las marcas generadas por otros agentes: los únicos identificados fueron roedores y con una baja incidencia (menos del $3 \%$ del NISP). Así, y pese a que la puna transicional de Chaschuil es un área con presencia de zorros y pumas, el conjunto A12-UEIII no fue modificado por estos agentes. Esto se diferencia de lo observado por Mondini (1997) en A7 de la misma formación rocosa donde se destaca un conjunto arqueofaunístico de baja resolución e integridad dado el uso alternado de dicho alero por humanos y carnívoros. Volviendo a A12, si se considera la meteorización, los restos óseos exhiben un muy buen estado de preservación, presentando el $98,4 \%$ del NISP un estadio 0,1 o 2 (con la mayor frecuencia en estadio 0 ). Esto último sugiere que la exposición de los restos a factores atmosféricos fue breve en el tiempo, con un relativamente rápido enterramiento por algún proceso sedimentario. Respecto a esto último, Kligmann (2009) señala que el origen de los sedimentos de la UEIII fue principalmente eólico. Asimismo, cabe señalar que, dado que se trata de un alero, la propia protección del abrigo rocoso debe haber colaborado en una menor incidencia de los diversos mecanismos fisicoquímicos que provocan la destrucción ósea. Así, se corrobora lo planteado por Kligmann (2009) acerca de la alta integridad de la UEIII mediante una línea de evidencia independiente: la zooarqueológica.

Tabla 2. Clases de edad de Camelidae del conjunto A12-UEIII

Table 2. Age classes of Camelidae from the A12-UEIII assemblage

\begin{tabular}{|c|c|c|c|c|}
\hline \multirow{2}{*}{ Etapas de fusión } & \multicolumn{4}{|c|}{ A12-UEIII } \\
\cline { 2 - 4 } & NISP F & NISP NF & $\%$ SUP & $\%$ MOR \\
\hline Temprana (<12-18 meses) & 3 & 0 & 100,0 & 0,0 \\
\hline Intermedia (<18-36 meses) & 8 & 6 & 57,1 & 42,9 \\
\hline Tardía (<36-48 meses) & 2 & 2 & 50,0 & 50,0 \\
\hline Total & 13 & 8 & 61,9 & 38,1 \\
\hline
\end{tabular}


Las actividades humanas en la ocupación de A12

A continuación, se discuten cuáles fueron concretamente las actividades humanas vinculadas a los animales llevadas a cabo en A12. El análisis taxonómico muestra que los camélidos son los más abundantes en el conjunto. Si se considera que los especímenes de Artiodactyla también corresponden a Camelidae, dado que no se registró otro taxón de dicho orden, la predominancia es casi absoluta. Así, los camélidos fueron los animales mayoritariamente consumidos durante la ocupación del alero, tal y como lo sugieren las marcas de procesamiento identificadas en especímenes asignados tanto a Camelidae como a Artiodactyla (corte, machacado y percusión). Además, si se considera la información osteométrica, los camélidos aprovechados habrían sido vicuñas. Son muchos los sitios arqueológicos puneños de sociedades agropastoriles que presentan una abundancia considerable de Vicugna vicugna, mostrando en algunos casos, y al igual que en A12, una predominancia absoluta (e.g. Real Grande 1 y 6) (Olivera y Grant 2009). A escala local, por un lado, las ocupaciones contemporáneas e incaicas de San Francisco y Las Coladas también presentan una marcada predominancia de vicuñas. Sin embargo, los contextos son distintos dado que no se trata de aleros ni cuevas sino de complejos de estructuras imperiales con un patrón arquitectónico de tipo RPC. Por otro lado, en la puna transicional de Chaschuil se han registrado también ocupaciones preincaicas (ca. 1700-800 años AP) con predominancia de vicuñas; aunque, nuevamente, no se trata de abrigos rocosos (ver más adelante) (Miyano 2019; Miyano et al. 2017; Ratto et al. 2012).

En A12 los roedores y las aves aparecen en muy bajas frecuencias. Dado que no presentan marcas de origen antrópico, no podemos sostener su procesamiento. Sin embargo, no se descarta que la presencia de los restos óseos de Rodentia, Chinchillidae y Aves en A12-UEIII se deba al transporte humano para su aprovechamiento; más aún considerando que no se ha identificado la acción de carnívoros. Además, estudios zooarqueológicos tanto en la puna transicional de Chaschuil como en otros sectores puneños han planteado el aprovechamiento de dichos taxones (Miyano et al. 2017; Urquiza y Echevarría 2018; Yacobaccio et al. 1997-1998).

Así, se sostiene que la ocupación del alero estuvo relacionada con actividades de caza, fundamentalmente de vicuñas. La presencia de dos fragmentos de cabezales líticos asociados a los restos óseos (Luna 2001) es coherente con esta propuesta y apuntan al uso de arco y flecha como técnica de captura, posiblemente realizada en las cercanías del sitio. Esto se sostiene debido a que se encuentran representadas la gran mayoría de las partes esqueletarias, sugiriendo un ingreso completo de los animales al alero para su procesamiento. En tanto, la presencia de tres raspadores y un cuchillo asociados a los restos óseos (Luna 2001) apoyan el procesamiento in situ de las carcasas.
Sin embargo, se ha destacado una mayor abundancia relativa de los elementos óseos del esqueleto apendicular por sobre los del axial. Esta diferencia en la representación anatómica puede tener dos causas que no son excluyentes. Por un lado, dicha representación puede ser explicada a partir del consumo y descarte de unidades anatómicas correspondientes al esqueleto apendicular en el contexto del alero y del transporte de las del esqueleto axial para su consumo diferido, almacenamiento y/o intercambio. Esta interpretación es sostenida no solo por la abundancia anatómica previamente destacada sino también por las correlaciones del \%MAU con los distintos índices utilizados. Respecto al esqueleto apendicular, las correlaciones tanto con el IM como con el IC fue positiva y significativa, sugiriendo una mayor representación de las partes esqueletarias apendiculares con abundante carne y médula (fémur y húmero presentan el \%MUA más alto). Sin embargo, el consumo de dichos recursos nutricionales no se restringió solo a las partes de mayor rinde económico dado que se registraron marcas de percusión en especímenes de metapodios y falanges que podrían estar vinculados al consumo de médula. En tanto, la correlación con el IS marca una ausencia significativa de elementos óseos con las mejores características para el proceso de secado con hueso: unidades anatómicas con escasa/nula médula ósea. Así, es posible que durante la ocupación del alero se haya secado carne con hueso para ser conservada y transportada.

Por otro lado, la diferencia en la representación anatómica entre el esqueleto apendicular y el axial puede deberse también a una mayor intensidad en el procesamiento de este último. Vinculado a ello, la presencia de marcas de procesamiento en especímenes de pelvis y costillas indica que también se produjo el consumo in situ de este segmento del esqueleto. Además, los índices NISP:MNE y NSP:NISP muestran que el esqueleto axial se encuentra más fragmentado que el apendicular y que la fragmentación del conjunto en general es alta. Así, resulta posible que los ocupantes de A12 no solo hayan reservado ciertas partes del esqueleto axial para su secado y consumo diferido sino que también hayan procesado intensamente otras partes para su consumo directo en el alero.

Las clases de edad de los camélidos representadas muestran un relativo equilibrio entre animales adultos (mayores a 36-48 meses) y subadultos (menores a 3648 meses). Si bien el perfil etario fue construido a partir de especímenes de Camelidae, el tamaño relativo de los restos óseos y la identificación exclusiva de vicuñas mediante el análisis osteométrico nos permite atribuir dicho perfil etario a Vicugna vicugna. Estos resultados se diferencian de aquellos observados en la ocupación incaica de San Francisco en donde se ha registrado una contundente predominancia de vicuñas adultas por lo que se propuso una caza dirigida a animales de más de 36-48 meses de edad: entre un $63-66 \%$ de los animales 
sobrevivieron a los 4 años (Miyano et al. 2017). En tanto, la supervivencia de las vicuñas en el caso de A12 fue menor: entre un 50-57\% habrían sobrevivido a los 36-48 meses de edad. Así, en A12 existe un aparente equilibrio entre vicuñas subadultas y adultas. Cabe señalar que el número de especímenes analizados para la construcción del perfil etario en la ocupación incaica de San Francisco fue de 119 mientras que en A12 se trató de 21. Así, la comparación entre ambos conjuntos debe ser considerada con precaución. Sin embargo, creemos que la diferencia en el perfil etario es sugerente y debemos considerarla al momento de discutir e integrar este resultado con otros (ver más adelante).

Finalmente, otro dato relevante es la presencia de un espécimen óseo de Artiodactyla con evidencia de formatización. Esto sugiere que los humanos no solo aprovecharon los recursos nutricionales de los animales, sino que también a partir de sus huesos manufacturaron artefactos. En este caso, no pudo identificarse el tipo de instrumento ni su funcionalidad, pero la mera presencia de una punta roma pulida denota la intención de formatización. Respecto al uso tecnológico de los recursos que brindan las vicuñas, tampoco se debe descartar el aprovechamiento del cuero y la fibra.

Hasta aquí hemos planteado las actividades humanas vinculadas a los animales realizadas en A12. Dado que Kligmann (2009) sostiene que las ocupaciones fueron breves y de baja intensidad, se propone que grupos poco numerosos habitaron temporalmente el abrigo rocoso y cazaron distintos animales silvestres en sus inmediaciones, entre las que se destacaron las vicuñas. Parte de estos camélidos fueron consumidos in situ mientras que algunas partes esqueletarias pudieron haber sido secadas para su consumo diferido, almacenamiento y/o intercambio.

Los ocupantes de A12: ¿fuera del control imperial? Al comienzo del trabajo se propuso discutir la relación de la ocupación del A12 con otros sitios cercanos y cuyos fechados radiocarbónicos también corresponden al momento de la ocupación incaica de la región. Se ha destacado que San Francisco, Las Coladas, San Francisco-04 y Fiambalá 1 se constituyen como un sistema de asentamientos vinculados a prácticas ceremoniales y festivas promovidas por el Estado y relacionados con el ascenso a los volcanes Incahuasi y/o San Francisco (Orgaz y Ratto 2013, 2015; Ratto y Orgaz 2009; Orgaz et al. 2019). Aclaramos que estas prácticas se llevaron a cabo también en otros sitios incas, tanto de nuestra región de estudio como en los valles del oriente (Giovanetti 2016; Valderrama y Giovanetti 2019). Sin embargo, a partir de la arqueofauna aquí analizada y el resto de la evidencia arqueológica asociada (cerámica, lítico, sedimentos), consideramos que la ocupación del A12 no se relaciona con el sistema de sitios imperiales anteriormente destacado. Las únicas evidencias para sostener dicha relación podrían ser: a) la proximidad espacial entre A12 y San Francisco; y b) los fechados contemporáneos de todos los sitios mencionados. Creemos que dichas evidencias no son suficientes para considerar a A12 como parte de dicho sistema de sitios incaicos y que otro escenario puede explicar su ocupación. Así, sostenemos que la ocupación de A12 corresponde a su uso por miembros de las sociedades agropastoriles de la región quienes desarrollaron prácticas de caza sin vínculos con las prácticas de comensalismo político y ceremonias incaicas llevados a cabo en la puna transicional de Chaschuil y, por lo tanto, fuera del dominio imperial. Respecto a esta interpretación, a continuación destacamos algunos puntos relacionados con: a) el sitio y su área emplazamiento; b) la información taxonómica y etaria del conjunto Camelidae de A12; c) la estrategia incaica de dominio en el oeste tinogasteño; y d) la proveniencia de los grupos humanos que ocuparon A12.

En primer lugar, y respecto al sitio, hemos destacado al inicio de este trabajo que el uso de cuevas y aleros fue habitual entre las sociedades agropastoriles prehispánicas de la puna argentina. A escala local, A7 y Las Cuevas 1 también presentan fechados para momentos incaicos por lo que el uso de aleros durante la ocupación imperial de la puna transicional de Chaschuil fue una práctica usual y A12 no se trataría de un caso aislado. Respecto al área de emplazamiento, el sector norte de la puna transicional de Chaschuil cuenta con evidencia de su ocupación por sociedades agropastoriles desde, por los menos, los ca. 1800 años AP (Ratto et al. 2012), marcando así un uso recurrente a lo largo del tiempo. Por ejemplo, sitios como El Zorro y El Corral y la ocupación preincaica de San Francisco (fechados entre los ca. 1700-800 años AP y también circundantes a la vega San Francisco) han sido propuestos como asentamientos de ocupación estacional/ temporal vinculados a la caza de vicuñas y al pastoreo de llamas (Miyano 2019; Ratto et al. 2012). En este marco, A12 muestra una continuidad en tiempos incaicos en el uso de estas tierras altas puneñas para el desarrollo de prácticas cinegéticas.

En segundo lugar, y vinculado a lo anterior, hemos destacado que las prácticas de caza en A12 se concentraron fundamentalmente en vicuñas, posiblemente a partir de la cacería individual mediante el uso de arco y flecha. El análisis del perfil etario ha mostrado que aparentemente no hubo una selectividad en las vicuñas capturadas. Este escenario es distinto al propuesto para la ocupación incaica contemporánea de San Francisco en la que la caza de vicuñas se encontraba dirigida a animales adultos (Miyano et al. 2017). Aquí cabe recordar que para la puna transicional de Chaschuil durante la ocupación incaica se ha propuesto la captura colectiva de vicuñas, la cual se encontraba sumamente regulada: se prohibía el sacrificio de animales jóvenes y se sacrificaban viejos y enfermos (Orgaz y Ratto 20022004). Así, la información etaria disponible para las 
vicuñas de A12 combinada con el contexto arqueológico nos permite hipotetizar que la caza realizada por los ocupantes del alero no se desarrolló bajo tal marco regulatorio. Respecto a esto, sitios con ocupaciones preincaicas como El Zorro y El Corral presentan perfiles etarios similares, indicando que la captura de vicuñas no se concentró en individuos adultos (Miyano 2019). De esta manera, la modalidad de caza de vicuñas en A12 parece ser una continuidad de lo realizado en momentos previos: captura individual y sin una selectividad marcada. El tamaño de los conjuntos arqueofaunísticos puede apoyar esta diferencia en la escala de apropiación de las vicuñas entre A12 (caza individual) y la ocupación incaica de San Francisco (caza colectiva). Mientras que, por un lado, la densidad del NISP en A12 es de 103,7 por $\mathrm{m}^{3}$; por otro lado, la densidad del NISP en San Francisco es de 440,1 y 206,9 para el Recinto 12 y Patio respectivamente (Miyano et al. 2017).

En tercer lugar, y respecto a la presencia incaica en el oeste tinogasteño, Orgaz y Ratto $(2013,2015)$ han planteado que el imperio se emplazó sobre lugares e instalaciones con historias previas, manipulando así la memoria colectiva local como método de dominación. Mientras que en algunos casos los incas llevaron a cabo modificaciones arquitectónicas en los sitios prexistentes marcando así su presencia de manera categórica; en otros casos ocuparon sitios sin llevar a cabo cambios a nivel estructural. Por un lado, en las tierras bajas del oeste tinogasteño su presencia fue permanente. Esto se observa por ejemplo en sitios de grandes dimensiones del valle de Fiambalá, como Mishma 7 o Batungasta, este último asociado con el alfar de La Troya empleado para la producción de bienes cerámicos. Por otro lado, en las tierras altas la presencia incaica no fue permanente. Como hemos visto, en el caso concreto del sector norte de la puna transicional de Chaschuil, se propuso que los incas promovieron fiestas en donde se consumieron y compartieron bebidas alcohólicas y alimentos y se organizaron incursiones hacia los volcanes Incahuasi y San Francisco. Dichas celebraciones, que buscaron legitimar su presencia en la región, fueron acotadas en el tiempo (Orgaz y Ratto, 2015; Ratto y Orgaz 2009). Esto último habría permitido que dicho espacio fuera ocupado y utilizado por grupos agropastoriles sin el control del Estado, desarrollando actividades vinculadas a su subsistencia sin encontrarse regidas por las directrices imperiales (e.g. regulación en la caza de vicuñas). Así, el contexto arqueológico de A12 sería un testimonio material de la actividad de dichos grupos.

Por último, y vinculado a lo anterior, resta resolver la siguiente pregunta: ¿quiénes fueron concretamente aquellos que ocuparon $\mathrm{A} 12$ y cazaron vicuñas por fuera del control imperial? Como ya hemos destacado, los datos arqueológicos y sedimentarios de A12 nos hacen pensar que se trató de un grupo humano reducido $y$, dado que la ocupación fue temporal, dicho grupo necesariamente debía habitar de manera permanente en otro espacio. En este sentido, tres alternativas surgen para explicar la proveniencia de los cazadores de A12. Por un lado, y si consideramos el esquema de poblamiento propuesto por Ratto (2013), ese pequeño grupo de personas podría ser parte de las sociedades agropastoriles locales cuya historia de ocupación del oeste tinogasteño es profunda y, por lo tanto, presentaban un conocimiento acabado del paisaje físico y social. Así, el área precordillerana (sierras de Narváez y cordillera de San Buenaventura) se constituye como una de las candidatas al emplazamiento de los sitios residenciales de los cazadores del A12. No obstante, las investigaciones arqueológicas desarrolladas en dicha área aún no han identificado sitios con fechados contemporáneos a la ocupación de $\mathrm{A} 12$, siendo el más cercano cronológicamente uno de los obtenidos para la aldea Casa del Medio (846₫45 años AP, AA89940, carbón) (Ratto et al. 2015). Así, consideramos que futuras intervenciones y prospecciones del área precordillerana podrán otorgar nuevos datos que permitan evaluar la presencia de asentamientos residenciales cuya ocupación sea simultánea a la de A12 y no presenten influencia inca. Por otro lado, y como segunda alternativa, resulta posible que los cazadores de A12 sean integrantes de grupos trasandinos de la actual región de Atacama (Chile) que realizaron incursiones a la vertiente andina oriental y cuyos sitios de ocupación permanente se encuentren del otro lado de la cordillera de los Andes. Por último, y como una tercera alternativa, no se debe descartar que estos grupos provengan del norte. En este sentido, el actual territorio de Antofagasta de la Sierra (Catamarca) se constituye como una potencial área de ocupación permanente de esas poblaciones. En dicha región se ha planteado un modelo de asentamiento y movilidad en donde las sociedades agropastoriles se establecieron en bases residenciales de ocupación estable principalmente en los sectores más bajos (3400-3550 msnm) y se movilizaban a zonas más altas (3900-4900 msnm) para el pastoreo de llamas y caza de camélidos silvestres (Olivera 1997). Así, el uso de A12 podría ser el resulta de una incursión hacia el sur de las poblaciones del actual territorio de Antofagasta de la Sierra en búsqueda de vicuñas.

Más allá de quiénes fueran efectivamente los grupos humanos que ocuparon A12 y si estos provenían del este, oeste o norte, podemos hipotetizar que este alero (y posiblemente también A7 y Las Cuevas 1) funcionó como un puesto de altura al que recurrían los grupos que residían de manera permanente en otra región para cazar vicuñas, generando así un sistema de asentamientos y un circuito de movilidad por fuera del control imperial.

En suma, a partir del análisis zooarqueológico de la UEIII de A12 fue posible dar cuenta de las actividades humanas vinculadas a los animales allí desarrolladas. Si bien su ubicación temporal y espacial muestra 
contemporaneidad y proximidad con sitios incaicos donde se realizaron eventos festivos y prácticas ceremoniales, consideramos que $\mathrm{A} 12$ no formó parte de dicho sistema de asentamientos. En cambio, A12 otorga evidencia material del uso temporal de la puna transicional de Chaschuil durante la ocupación incaica pero por parte de miembros de las sociedades agropastoriles de la región sin relación evidente con las estrategias y/o autoridades imperiales.

26 de junio de 2020, Ciudad Autónoma de Buenos Aires

\section{Bibliografía}

Aschero, C. \& Yacobaccio, H. (1998-1999). 20 años después: Inca Cueva 7 reinterpretado. Cuadernos del Instituto Nacional de Antropología y Pensamiento Latinoamericano, 18, 7-18.

Behrensmeyer, A. (1978). Taphonomic and Ecologic Information from Bone Weathering. Paleobiology, 5, 150-162

Bianchi, A., \& Cravero, S. (2010). Atlas climático regional digital de la República Argentina. Salta-Jujuy: Ediciones del Instituto Nacional de Tecnología Agropecuaria.

Binford, L. (1984). Faunal Remains from Klasies River Mouth. New York: Academic Press.

Borrero, L. (1990). Fuego-Patagonian Bone Assemblages and the Problem of Communal Guanaco Hunting. En L. Davis \& B. Reeves (eds.), Hunters of the Past (pp. 373399). Londres: Unwin Hyman.

Cabrera, A. \& Willink, A. (1973). Biogeografía de América Latina. Washington: OEA.

Cordomí, A. (2012). Tafonomía de camélidos en Punta de la Peña (PP4), (Ca. 1500 al 500 AP). Antofagasta de la Sierra. Catamarca. Comechingonia, 6(2), 176-222.

De Nigris, M. (2004). El consumo en grupos cazadores recolectores: Un ejemplo zooarqueológico de Patagonia meridional. Buenos Aires: Publicaciones de la Sociedad Argentina de Antropología.

De Nigris, M. \& Mengoni Goñalons, G. (2005). The guanaco as a source of meat and fat in the Southern Andes. En J. Mulville \& A. Outram, The zooarchaeology of fats, oils and dairying (pp. 60-166). Oxford: Oxbow Books.

Elkin, D. (1995a). El uso del recurso fauna por los primeros habitantes de Antofagasta de la Sierra (Puna de Catamarca). Actas del I Congreso de Investigación Social: Región y sociedad en Latinoamérica, su problemática en el noroeste argentino: (pp. 202-209). Tucumán.
Elkin, D. (1995b). Volume Density of South American Camelid Skeletal Parts. International Journal of Osteoarchaeology, 5, 29-37.

Erramosupe, V., Urquiza, S. \& Aschero, C. (2017). Manejo de camélidos durante el Formativo temprano en la Puna Seca de Jujuy (Argentina). Intersecciones en Antropología, 18, 295-303.

Giovannetti, M. (2016). Fiestas y ritos Inka en El Shincal de Quimivil. Buenos Aires: Editorial Punto de Encuentro.

Izeta, A. (2007). Zooarqueología del Sur de los Valles Calchaquíes: Estudio de conjuntos faunísticos del Periodo Formativo [tesis de doctorado, Universidad Nacional de La Plata]

Kent, J. (1982). The domestication and exploitation of the South American camelids: Methods of analysis and their application to circum-lacustrine archaeological sites in Bolivia and Peru [tesis de doctorado, Washington University]

Klein R., \& Cruz-Uribe, K. (1984). The Analysis of Animal Bones from Archaeological Sites. Chicago: University of Chicago Press.

Kligmann, D. (2009). Procesos de formación de sitios arqueológicos: Tres casos de estudio en la Puna Meridional catamarqueña argentina. Oxford: British Archaeological Reports

Kligmann, D. \& Ratto, N. (2009). Aportes de la sedimentología a la arqueología: el caso del sitio Fiambalá 1 (puna meridional catamarqueña). En O. Palacios, C. Vázquez, T. Palacios \& E. Cabanillas (eds.), Arqueometría latinoamericana: 2do. Congreso Argentino y Primero Latinoamericano (pp. 199-208). Buenos Aires: Comisión Nacional de Energía Atómica.

Kligmann, D., Sesé, C. \& Barbadillo, J. (1999). Análisis tafonómico de la fauna de microvertebrados del Alero 12 (Puna meridional catamarqueña argentina) y sus implicancias para el comportamiento humano. Arqueología, 9, 9-48.

Lantos, I., Spangenberg, J., Giovannetti, M., Ratto N. \& Maier, M. (2015). Maize consumption in pre-Hispanic south-central Andes: Chemical and microscopic evidence from organic residues in archaeological pottery from western Tinogasta (Catamarca, Argentina). Journal of Archaeological Science, 55, 83-99.

Lavallée, D., Julien, M., Karlin, C., García, L., Pozzi-Escot, D. \& Fontugne, M. (1997). Entre Desierto y Quebrada: Tomayoc, un alero en la Puna. Avances en Arqueología, 3, 9-39. 
López, G. (2009a). Arqueofaunas, osteometría y evidencia artefactual en Pastos Grandes, Puna de Salta: Secuencia de cambio a lo largo del Holoceno temprano, medio y tardío en el sitio Alero Cuevas. Intersecciones en Antropología, 10, 105-119.

López, G. (2009b). Diversidad arqueológica y cambio cultural en Pastos Grandes, Puna de Salta, a lo largo del Holoceno. Relaciones de la Sociedad Argentina de Antropología, 34, 149-175.

López, G., Coloca, F., Araya, S., Orsi J. \& Seguí, S. (2015). El sitio Cueva Inca Viejo, Salar de Ratones, Puna de Salta: evidencia arqueológica y procesos de interacción macrorregional. Relaciones de la Sociedad Argentina de Antropología 40(1):45-71.

López, G., Coloca, F., Orsi, J., Araya, S., Seguí, S., Rosenbusch, M. \& Solá, P. (2018). Ocupación incaica en Cueva Inca Viejo y Abra de Minas, puna de Salta, Argentina: minería de turquesa y prácticas rituales. Estudios Atacameños. En prensa.

Luna, M. (2001). Integración de contextos líticos superficiales y subsuperficiales en la cuenca superior del valle de Chaschuil (Dpto. Tinogasta, Catamarca, República Argentina). Arqueología Espacial, 23, 199-225.

Lyman, R. (1994). Vertebrate Taphonomy. New York: Cambridge University Press.

Lyman, R. (2008). Quantitative Paleozoology. Cambridge: Cambridge University Press.

Madrazo, G. \& Ottonello, M. (1966). Tipos de instalación prehispánica en la región de la Puna y su borde. Olavarría: Museo Etnográfico Municipal Damaso Arce.

Marean, C. \& Frey, C. (1997). Animal bones from caves to cities: reverse utility curves as methodological artifacts. American Antiquity, 62, 698-716.

Mengoni Goñalons, G. (1999). Cazadores de guanacos de la estepa Patagónica. Buenos Aires: Publicaciones de la Sociedad Argentina de Antropología.

Mengoni Goñalons, G. (2013). El aprovechamiento de la fauna en sociedades complejas: aspectos metodológicos y su aplicación en diferentes contextos arqueológicos del NOA. En V. Williams \& M. Cremonte (comps.), Al borde del imperio. Paisajes sociales, materialidad y memoria en áreas periféricas del noroeste argentino (pp. 311-396). Buenos Aires: Publicaciones de la Sociedad Argentina de Antropología.

Mengoni Goñalons, G. \& De Nigris, M. (1999). Procesamiento de huesos largos de guanaco en Cerro de los Indios 1 (Santa Cruz). Soplando en el viento. Actas de las Terceras Jornadas de Arqueología de la Patagonia (pp. 461-475). Neuquén-Buenos Aires.

Miyano, J. (2019). Humanos y animales en el oeste tinogasteño (Catamarca, Argentina): su relación a lo largo del tiempo desde el siglo IV a.C. hasta la actualidad [tesis de doctorado, Universidad de Buenos Aires]

Miyano, J., Lantos, I., Ratto, N. \& Orgaz, M. (2017). Animales e incas en el oeste tinogasteño (Catamarca, Argentina). Latin American Antiquity, 28, 28-45.

Mondini, M. (1997). Alero 7- Sector B (Las Grutas, Vegas de San Francisco). Análisis faunístico. Informe de actividades del Proyecto Arqueológico Chaschuil. Ms.

Mondini, M. \& Muñoz, S. (2017). Osteometrics of SouthCentral Andean wild camelids: new standards. En M. Mondini, S. Muñoz \& P. Fernández (eds.), Zooarchaeology in the neotropics. Environmental diversity and humananimal interactions (pp. 177-188). Cham: Springer.

Morlans, C. 1985. Regiones naturales de Catamarca, provincias geológicas y provincias fitogeográficas. San Fernando del Valle de Catamarca: Editorial Científica Universitaria.

Olivera, D. (1997). La importancia del Recurso Camelidae en la Puna de Atacama entre los 10.000 y 500 años AP. Estudios Atacameños, 14, 29-41.

Olivera, D. \& Grant, J. (2008). Economía y ambiente durante el Holoceno tardío (ca. 4500-400) de Antofagasta de la Sierra (Puna meridional argentina). En A. Acosta, D. Loponte \& L. Mucciolo (comps.), Temas de Arqueología: Estudios Tafonómicos y Zooarqueológicos I (pp. 99131). Buenos Aires: Instituto Nacional de Antropología y Pensamiento Latinoamericano.

Olivera, D. \& Grant, J. (2009). Puestos de altura en la Puna argentina: Zooarqueología de Real Grande 1 y 6 y Alero Tomayoc. Revista del Museo de Antropología, 2, 151-168.

Olivera, D., Vidal, A. \& Grana, L. (2003). El sitio Cueva Cacao 1A: hallazgos, espacio y proceso de complejidad en la puna meridional (ca. 3000 años AP). Relaciones de la Sociedad Argentina de Antropología, 28, 257-270.

Orgaz, M. (2002). Presencia inkaica en los Andes Meridionales: caso de estudio en la cabecera norte del valle de Chaschuil (Tinogasta, Catamarca). San Fernando del Valle de Catamarca: CENEDIT.

Orgaz, M., Feely, A. \& Ratto, N. (2007). La cerámica como expresión de los aspectos socio-políticos, económicos y rituales de la ocupación Inka en la puna de Chaschuil y el valle de Fiambalá (Departamento Tinogasta, Catamarca, 
Argentina). En A. Nielsen, M. Rivolta, V. Seldes, P. Mercolli \& M. Vázquez, Procesos Sociales Prehispánicos en los Andes Meridionales (pp. 237-258). Córdoba: Editorial Brujas.

Orgaz, M., I. Lantos \& N. Ratto. 2019. Comensalismo y bebidas durante la ocupación inca en las tierras altas de Chaschuil (Tinogasta, Catamarca, Argentina). Actas del XX Congreso Nacional de Arqueología Chilena (pp.145-160). Editorial de la universidad de Concepción, Concepción.

Orgaz, M. \& Ratto, N. (2013). Fragmentos del pasado en la ocupación incaica del oeste tinogasteño (Catamarca). En N. Ratto (comp.), Delineando prácticas de la gente del pasado. Los procesos socio-históricos del oeste tinogasteño (Catamarca) (pp. 311-333). Buenos Aires: Publicaciones de la Sociedad Argentina de Antropología.

Orgaz, M. \& Ratto, N. (2015). Estrategias de ocupación incaica al sur del Tawantinsuyu (Tinogasta, Catamarca, Argentina): la apropiación de paisajes sagrados y la memoria social. Ñawpa Pacha, 35(2), 217-235.

Ratto, N. (1997). Proyecto Arqueológico Chaschuil 95-98. Dinámica cultural y ambiental. Uso del espacio por sociedades del pasado en la Puna meridional catamarqueña. Informe de Avance, Tomo I-II. Secretaría de Ciencia y Tecnología de la Universidad Nacional de Catamarca. Ms.

Ratto, N. (2003). Estrategias de caza y propiedades del registro arqueológico en la Puna de Chaschuil (Departamento Tinogasta, Catamarca) [tesis de doctorado, Universidad de Buenos Aires]

Ratto, N. (2013). A modo de introducción: la articulación de estudios arqueológicos, paleoambientales e históricos en el oeste tinogasteño (Catamarca). En Delineando prácticas de la gente del pasado. Los procesos sociohistóricos del oeste tinogasteño (Catamarca) (pp. 17-44). Buenos Aires: Publicaciones de la Sociedad Argentina de Antropología.

Ratto, N., Carniglia, D. \& Coll, L. (2012). Ocupación del área de "Los Seismiles" desde tiempos formativos a recientes (Departamento Tinogasta, Catamarca): Nuevas evidencias. Relaciones de la Sociedad Argentina de Antropología, 37, 207-216.

Ratto, N., Basile, M., Feely, A., Lantos, I., Coll, L., Carniglia, D \& Miyano, J. (2015). La gente y sus prácticas en las tierras bajas y altas del oeste tinogasteño en los siglos I a XIII D.C. (Catamarca, Argentina). En A. Korstanje, M. Lazzari, M., Basile, M. Bugliani, V. Lema, L. Pereyra Domingorena \& M. Quesada (eds.), Crónicas materiales precolombinas. Arqueología de los primeros poblados del Noroeste Argentino (pp. 215-145). Buenos Aires: Sociedad Argentina de Antropología.

Ratto, N. \& Orgaz, M. (2002-2004). La cacería en los Andes: registro material del chaku en la Puna meridional catamarqueña (Cazadero Grande, Tinogasta). Arqueología, 12, 72-102.

Ratto, N. \& Orgaz, M. (2009). Poder, control y volcanes: El estado Inka en el volcán Incahuasi (Tinogasta, Catamarca). En N. Ratto (comp.), Entrelazando ciencias: sociedad y ambiente antes de la conquista española (pp. 159-174). Buenos Aires: EUDEBA.

Ratto, N., Orgaz, M., de la Fuente, G. \& Plá, R. (2002). Ocupación de pisos de altura y contexto de producción cerámica durante el Formativo: El caso de la región puneña de Chaschuil y su relación con el Bolsón de Fiambalá (Depto. Tinogasta, Catamarca, Argentina). Estudios atacameños, 24, 51-69.

Urquiza, S. \& Aschero, C. (2014). Economía animal a lo largo del Holoceno en la Puna austral argentina: Alero Punta de la Peña 4. Cuadernos del Instituto Nacional de Antropología y Pensamiento Latinoamericano, 2, 86-112.

Urquiza, S. \& Echevarría, A. (2018). Zooarchaeology of flight: Avifauna resource from the Southern Argentine Puna. Journal of Archaeological Science: Reports, 18, 516-534.

Valderrama, M. \& Giovannetti, M. (2019). Animales y ritualidad en el mundo Inka. Un caso de estudio en el sitio arqueológico El Shincal de Quimivil (Londres, Catamarca). Comechingonia, 23(2), 11-35.

Vervoorst, F. (1951). Resultados de un viaje a la cuenca de Laguna Verde (Tinogasta-Catamarca) III. Observaciones sobre la vegetación entre Tinogasta y la cuenca. Actas de la XV Semana de Geografía (pp. 61-67). Mendoza.

Yacobaccio, H. (1994). Hilos conductores y nudos gordianos: Problemas y perspectivas en la arqueología de cazadores-recolectores puneños. Rumitacana. Revista de Antropología, 1, 19-21.

Yacobaccio, H., Catá, M., Morales, M., Solá, P., Alonso, M., Rosenbusch, M., Vázquez, C., Samec, C., Oxman, B. \& Cáceres, M. (2012). El uso de cuevas por pastores andinos: el caso de Cueva Quispe (Susques, Puna de Jujuy). En G. López \& H. Muscio (eds.), Arqueología de la Puna Argentina: Perspectivas actuales en el estudio de la diversidad y el cambio cultural (pp. 33-48). Oxford: British Archaeological Reports.

Yacobaccio, H., Lazzari, M., Guráieb, G. \& Ibañez, G. 
(2000). Los cazadores en el borde oriental de la puna. Arqueología, 10, 11-38.

Yacobaccio, H., Madero, C., Malmierca, M. \& Reigadas,
M. (1997-1998). Caza, domesticación y pastoreo de camélidos en la Puna Argentina. Relaciones de la Sociedad Argentina de Antropología, 22-23, 389418. 